\title{
LA ESCRITURA DE LA AGUJA. LÍNEA Y SUTURA EN LA OBRA DE CONCHA ROMEU
}

\author{
Sara GARCÍA FERNÁNDEZ
}

Universidad Nacional Autónoma de México

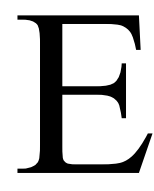

ste texto es una disección de las dos bases que a mi juicio sustentan el ejercicio de la costura como escritura: la línea (y su vinculación con el lenguaje) y la sutura (y su conexión con la narración). Este espíritu bicéfalo que habita la práctica de la costura - entendida no como acción funcional sino como acción poética — queda al desnudo en la obra de Concha Romeu (Madrid, 1954), donde se visibiliza y problematiza la complejidad alcanzada por esta técnica milenaria en su deriva más contemporánea.

Para entender el modo en el que nuestra artista pone en juego la esencia de la costura como escritura plástica, actualizando sus cualidades más propias y elevándola a un nivel de gran profundidad especulativa, es preciso iniciar un análisis de las dos bases señaladas. Comenzaré en primer lugar por la línea y, en páginas sucesivas, abordaré la sutura, de manera que surjan progresivamente el resto de los elementos participantes en el trabajo de Romeu.

\section{L-1́-n-e-a}

Por un lado, la costura se encuentra en relación directa con la línea en tanto esta es su forma más común de extensión espacial. Existe en la configuración más fundamental del acto de coser una necesidad de avance, de salir de sí, de extenderse lejos de su comienzo, así como de una prolongación sin final determinado. Excepto por una intención deliberada de terminar en un punto concreto, el gesto de coser no encuentra interrupción, pudiendo prolongarse hasta el infinito. Es su constitución circular (entrada en la tela - transcurso - salida de la tela - transcurso) la que hace de ella un movimiento cíclico eterno. Sin embargo, este movimiento continuado y permanente requiere del avance y, por tanto, de la línea. Pensemos en una rueda. Su constitución circular permite el desplazamiento siguiendo una línea, siendo este movimiento de avance el más constitutivo y por el que la rueda adquiere su sentido. Sucede así que la línea es la forma que satisface la necesidad de avance de la costura. 
Por otro lado, la línea es la arquitectura interna que sostiene la propia acción de coser, su condición de desarrollo. Es aquello que vertebra y permite que la construcción se desenvuelva aportando, además, unidad al conjunto.

$\mathrm{Al}$ atender a la relación estrecha de estas dos nociones, la linealidad en cuanto avance y en cuanto arquitectura, se detecta en la acción de caminar, andar, pasear (más adelante se abordarán sus diferencias) una analogía fértil a nivel interpretativo y de la que se pueden extraer conceptos que apuntalen una comprensión más amplia de la habitual sobre la costura. Abandonemos por un momento el orden de ideas que seguíamos y pensemos en la siguiente historia.

El 25 de diciembre de 1956 el escritor Robert Walser muere mientras pasea. Su cuerpo es encontrado tendido en la nieve en las cercanías del sanatorio de Herisau (Suiza), lugar en el que permaneció durante veintitrés años. La policía registra el hallazgo de su cadáver con algunas fotografías. Una de ellas, que imaginamos fue tomada de forma mecánica y sin ninguna intención estética, logra concentrar de manera inigualable la esencia del escritor. Ahí aparecen las huellas de sus pasos, aún frescos en la nieve, como testimonio de su última acción y, al mismo tiempo, como el mejor epitafio posible para aquel que había dedicado su vida a reflexionar caminando. En El paseo, uno de sus textos capitales así lo atestigua:

Estar muerto aquí, y ser enterrado sin llamar la atención en la fresca tierra del bosque, tendría que ser dulce. ¡Ah, si se pudiera sentir y gozar de la Muerte en la Muerte! Quizá es así. Sería hermoso tener en el bosque una tumba pequeña y tranquila. Quizá oyera el canto de los pájaros y el susurrar del bosque sobre mí. Lo desearía (Walser, 1917: 25).

En esa fotografía la línea trazada por los pies de Walser al borde de la muerte es la alegoría de su propia existencia, una manera concisa de expresar visualmente no solo cómo vivió sino qué pensaba sobre la vida. Si se piensa en esta secuencia de pasos como un pictograma se puede imaginar que representa conceptos como «pasear», «vida»o «camino». Si se piensa como texto escrito, entonces los pasos serán palabras; los vacíos entre ellos, espacios en blanco; las suelas de sus zapatos, la tipografía; la manera de pisar, su entonación o cadencia y, de manera literal, la huella será el significante. Sin embargo, de forma visual aparece representada la dialéctica ausencia-presencia, una relación intrínseca al caminar y también a la costura cuyas peculiaridades serán tratadas más adelante.

Desplazarse a pie ha generado una cantidad enorme de literatura y diversas denominaciones para sus protagonistas. Los gustos urbanos del flâneur de Baudelaire poco tienen que ver con el romántico Wanderer que inspiraba a Hölderlin o con el deambular del saunterer cuyos orígenes etimológicos rastreaba Thoreau. Cada uno de ellos practica una manera peculiar de andar, aunque más allá de tratarse de recorrido por la ciudad o por la naturaleza, el contraste radical se encuentra en la diferencia entre «pasear»y «caminar».

El paseante de Walser está más cercano al que describía Schelle en el Arte de Pasear y que se podría resumir en un individuo que concibe el paseo como puro deleite carente por completo de fatiga. Este hedonismo, enemigo de la prisa, se regocija en una percepción holística por la que todo adquiere sentido cuando se inserta en el fluir propio del paseo. «Al fin y al cabo, se trata más de un suave y 
delicado pasear que de un viaje y caminata, y más de un fino vagar que de un fuerte paso y marcha» (Walser, 1917: 25). Y se le atribuye un aprendizaje no solo estético sino también moral:

En realidad, el interés del paseante por la naturaleza debería ser de orden estético. Solo la contemplación estética de la naturaleza produce el libre juego de las facultades del alma [...]. Es ella también la que promueve de forma indirecta, gracias a las impresiones que causa con sus escenas sublimes y conmovedoras, el interés moral por la naturaleza (Schelle, 1802: 41).

Sin embargo, caminar contiene el anhelo de abrazar el estado salvaje. La naturaleza no aparece, como en textos anteriores, exotizada y percibida desde la seguridad del que incursiona brevemente en ella, sino que queda definida como el único lugar que permite verdaderamente caminar. En este sentido, tal vez sea Thoreau el que más puramente haya descrito el espíritu que anima esta práctica:

Tal vez tuviéramos que prolongar el más breve de los paseos, con imperecedero espíritu de aventura, para no volver nunca, dispuestos a que sólo regresasen a nuestros afligidos reinos, como reliquias, nuestros corazones embalsamados. Si te sientes dispuesto a abandonar padre y madre, hermano y hermana, esposa, hijo y amigos, y a no volver a verlos nunca; si has pagado tus deudas, hecho testamento, puesto en orden todos tus asuntos y eres un hombre libre; si es así, estás listo para una caminata (Thoreau, 1861: 1).

En este mismo texto, Thoreau reflexiona sobre la querencia de sus pasos con el Oeste, donde radica el futuro de la humanidad, al igual que el Este señala a la Historia. Caminar en una dirección determinada implica trazar una línea. Así como el paseo puede alterar su recorrido dependiendo de una inclinación momentánea, el caminar conoce su rumbo.

Esta digresión sobre las interpretaciones del andar permite ahora reparar en la injusticia cometida con el tratamiento dado hasta el momento a la costura. Ha sido habitual concebir la costura como el pasear, esto es, una actividad acotada, de poca transcendencia pública aunque gozosa para el que la practica, un disfrute íntimo, pausado, meditativo, solitario. Sin embargo, esta es solo la superficie. Las implicaciones de la costura en su profundidad más genuina son semejantes a las del caminar, precisamente por lo que esta tiene de escritura. La línea formada por las puntadas supone una dirección firme, consciente e implicada. Es una inscripción en la vasta extensión de la tela, un medio de difícil tránsito, que impide su horadación ofreciendo la resistencia de un bosque a ser penetrado. La costura, llegado este punto, se revela como voluntad, la materialización física de algo que es, en realidad, espiritual ${ }^{1}$.

Retomando el argumento principal de este texto, abordo ahora el modo particular de escribir de la costura, con la línea a la base, y su reflejo en la obra de Concha Romeu. Para esto, es necesario contar con el mayor reivindicador del concepto de escritura hasta la fecha, el filósofo francés Jacques Derrida. En su obra De la Gramatología reclama al concepto occidental de lenguaje el haberse convertido en el disfraz de una escritura primera. Cinematográfica, coreográfica, pictórica, escultórica, musical y hasta atlética, militar o política, esta escritura es todo lo pro-gramá-tico, un campo enorme y extraño por completo a la voz. Sin embargo, el fonocentrismo de la tradición metafísica ha resultado

\footnotetext{
${ }^{1}$ En este sentido, las conclusiones alcanzadas por Shopenhauer en El mundo como voluntad y representación pueden ser esclarecedoras. Valga el apunte como posible vía de reflexión.
} 
privilegiado de manera que el lenguaje (el sistema «oírse-hablar») aparece como lo originario mientras que la escritura queda relegada a una «función secundaria e instrumental» (Derrida, 1967: 5).

Derrida comienza entonces un proyecto de deconstrucción de la escritura pneumatológica, la que la tradición clásica vincula a la voz por su cercanía al alma, y de análisis de la gramatológica, aquella escritura relacionada hasta ahora con el cuerpo, esto es, con lo exterior.

\footnotetext{
Es necesario pensar ahora que la escritura es, al mismo tiempo, más externa al habla, no siendo su «imagen» o su «símbolo», y más interna al habla, que en sí misma es ya una escritura. Antes de estar ligada a la incisión, al grabado, al dibujo o a la letra, a un significante que en general remitiría a un significante significado por él, el concepto de grafía implica, como la posibilidad común a todos los sistemas de significación, la instancia de la huella instituida (Derrida, 1967: 44; énfasis del autor).
}

En este caso, hay dos ideas de este texto capital de Derrida que nos acercan a la comprensión de la costura como escritura. La primera es comprobar que la escritura no es solo aquello que tiene una grafía, esto es, una representación de un sonido, considerando la enorme ampliación del campo de la escritura que esto supone. Y, la segunda, la focalización en la huella, es decir, en la ausencia antes que en la presencia. Con el ejemplo de los últimos pasos de Walser antes de morir se apreciaba cómo esa escritura en la nieve estaba conformada fundamentalmente por la huella. Aquí es donde llegamos a la verdadera peculiaridad de la costura que hace de ella un modo de transcendencia hacia el origen, una forma de atender a lo otro más allá de nuestro lenguaje, siendo uno de los posibles caminos del pensamiento de la huella. «A partir de esto, para sacar el concepto de huella del esquema clásico que lo haría derivar de una presencia o de una no-huella originaria y que lo convertiría en una marca empírica, es completamente necesario hablar de huella originaria o de archi-huella» (Derrida, 1967: 59).

Si bien es cierto que la huella en la costura sigue remitiendo a la presencia, esta permanece en una dialéctica continua respecto a aquella. Mi intención no es, ni mucho menos, señalar la costura como operación paradigmática de la deconstrucción derridiana, sino como una de las escrituras donde la huella logra protagonismo. La tela es espacio tanto para la huella como para el «ente-presente», mientras que en la escritura pneumatológica la huella se busca exclusivamente en el significante. Al igual que Lucio Fontana abrió el espacio más allá de la superficie pictórica con su concetto spaziale realizando incisiones en el lienzo y dejando ver que existía un atrás ${ }^{2}$, esta misma dinámica de envéssuperficie se da en la costura con la salvedad de que no se constituyen como dos caras de una misma moneda (una de las cuales tan solo queda a la vista a través de la herida) sino como un mismo transcurrir. Aquí la importancia de la línea. La línea entra y sale de la tela de manera propia, ella es la que une huella y presencia. En la costura, la línea es la estructura que sustenta la dinámica descrita por Derrida y que pretende deconstruir. Mientras que en el lenguaje domina la presencia y la escritura queda supeditada, en la acción de coser ausencia y presencia se equilibran, favoreciendo la reflexión sobre la huella.

\footnotetext{
${ }^{2}$ http://www.tate.org.uk/art/artworks/fontana-spatial-concept-waiting-t00694 (última consulta, 19-6-2016).
} 

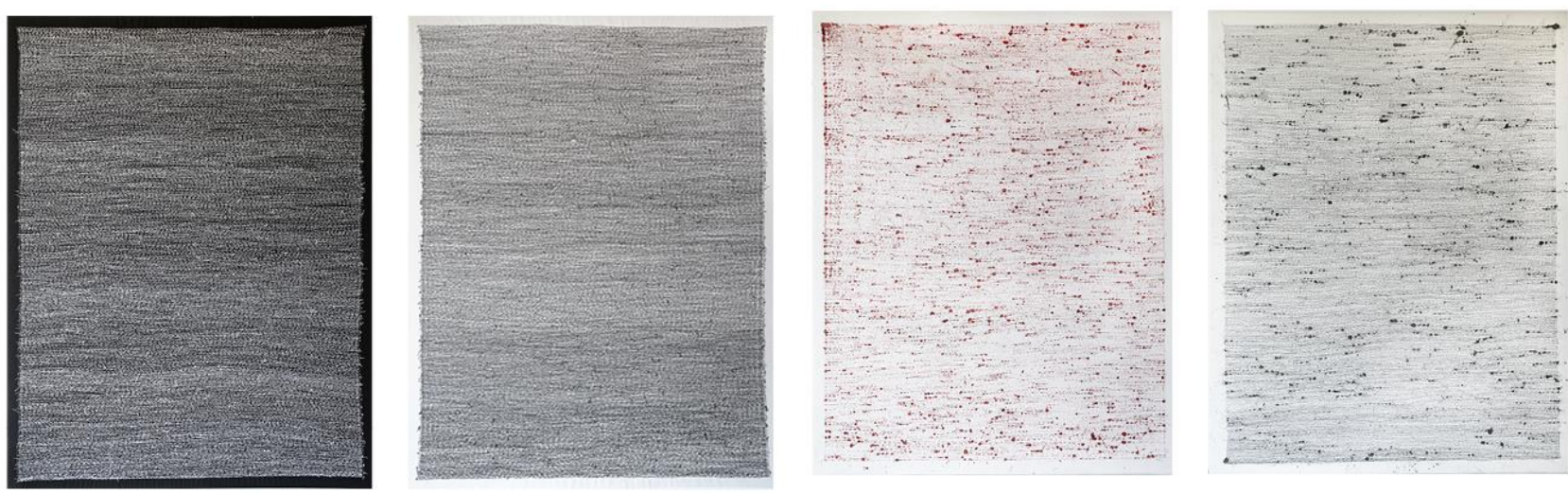

Fig. 1: Serie Biografías, 2013. Algodón e hilo. 81 x 65 cm. Imagen cortesía de la artista. Fotografía de Jesús Paniagua

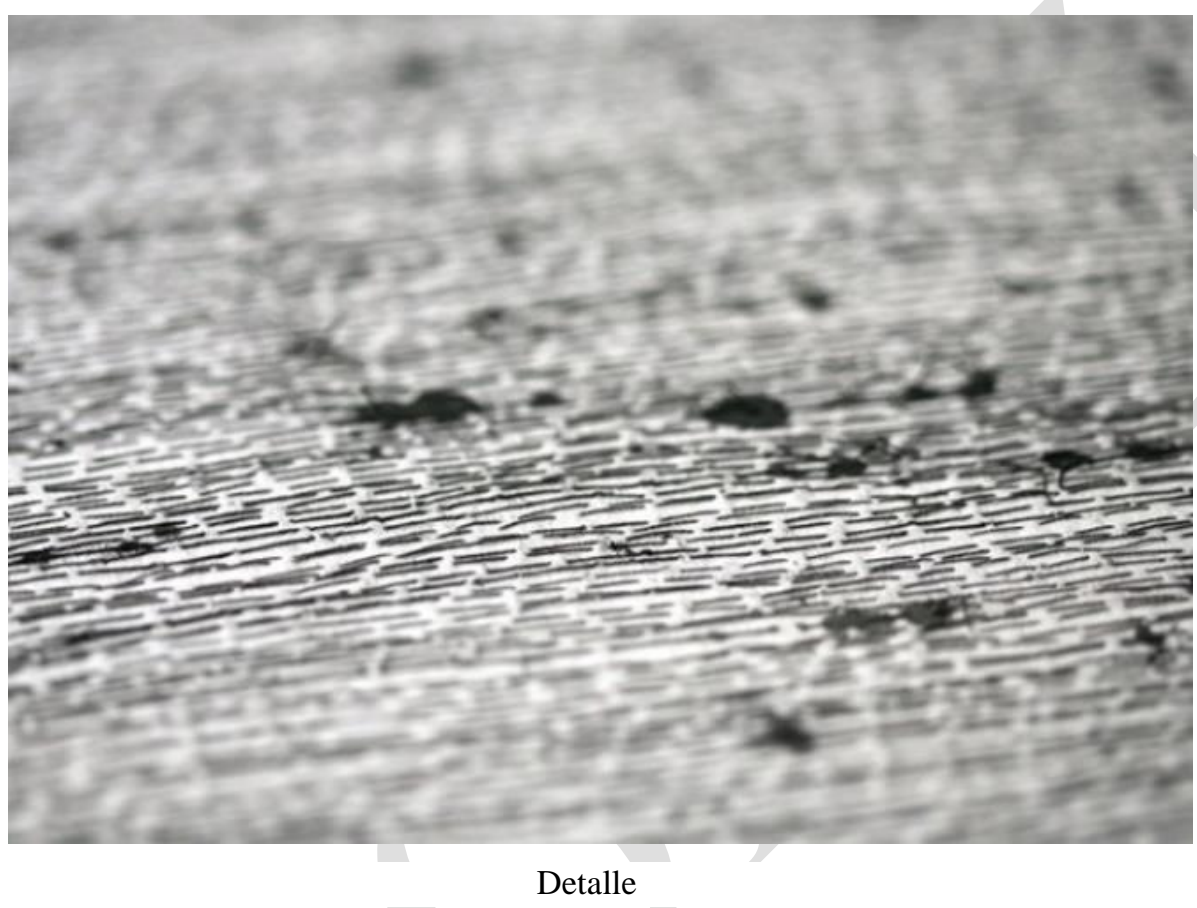

Detalle

Las obras que componen la serie Biografías [fig. 1] de Concha Romeu son descripciones de vidas anónimas y anodinas. Las líneas de puntadas se desarrollan de forma paralela unas a otras y se organizan en aspecto similar al de una página. Describen todos los momentos que componen una existencia desde el nacimiento hasta la muerte, aunque resultan indistinguibles unos de otros excepto por algunas manchas dispersas que aparecen en señal de un acontecimiento extraordinario. En el transcurso de la serie, el fondo y el hilo que lo ocupa van mimetizándose, dificultando la lectura. La información se pierde progresivamente, de manera que la existencia parece diluirse hasta desaparecer casi por completo. Resulta interesante observar cómo se mantienen los márgenes. Ese encuadre favorece la lectura y, al mismo tiempo, muestra la imposibilidad de escape. Hay una acotación originaria en ese espacio vital que impide cualquier desbordamiento. Las alusiones a la costura como escritura convierten a esta serie en un trabajo autorreferencial de gran interés y desvela una pauta interpretativa en la obra de Romeu.

Por ejemplo, en el libro de artista De la herida 4 [fig. 2] es el descosido el que construye la obra. El propio tejido de la tela, el lugar en el que la costura tiene lugar, es deshecho en señal de desgarramiento. Las páginas teñidas de rojo en sus lados se prolongan desestructuradas y se enredan imposibilitando su escritura y, sin embargo, conservando su soporte, el libro en este caso. La artista ejerce así una violencia estructural sobre la línea. 


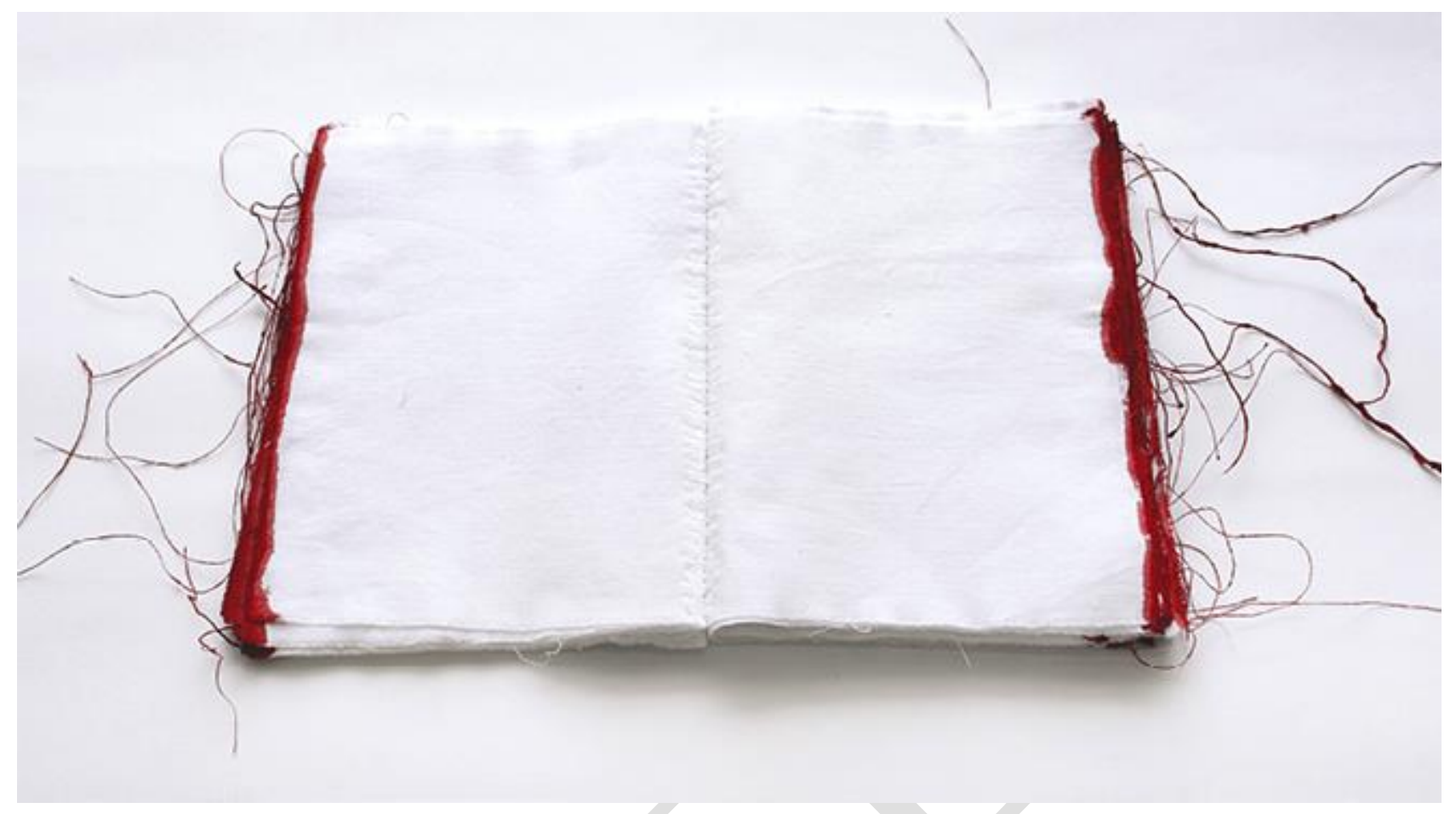

Fig. 2: De la herida, 2010. Acrílico sobre tela. 22 × 16 × $3 \mathrm{~cm}$. Imagen cortesía de la artista.

Fotografía de Jesús Paniagua

Además del coser y el descoser, Romeu emplea a menudo la sobrecostura, una herramienta que como estas otras pone al servicio de la disolución. Obras como Álbum de familia [fig. 3] o la serie de retratos femeninos A-mnesia (fig. 4) tienen imágenes a la base que son descodificadas gracias al empleo de la sobrescritura como atrofia. Esto resulta en cierta manera paradójico, pero precisamente porque el código empleado

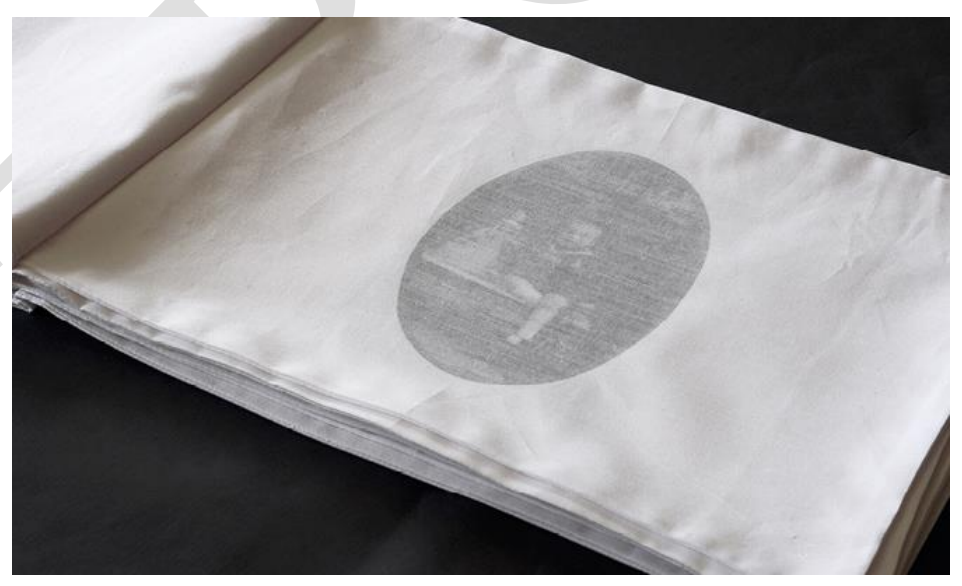

Fig. 3: Álbum de familia, 2013. Transferencia sobre tela. 32 × 24 x $2 \mathrm{~cm}$. Imagen cortesía de la artista. Fotografía de Jesús Paniagua.

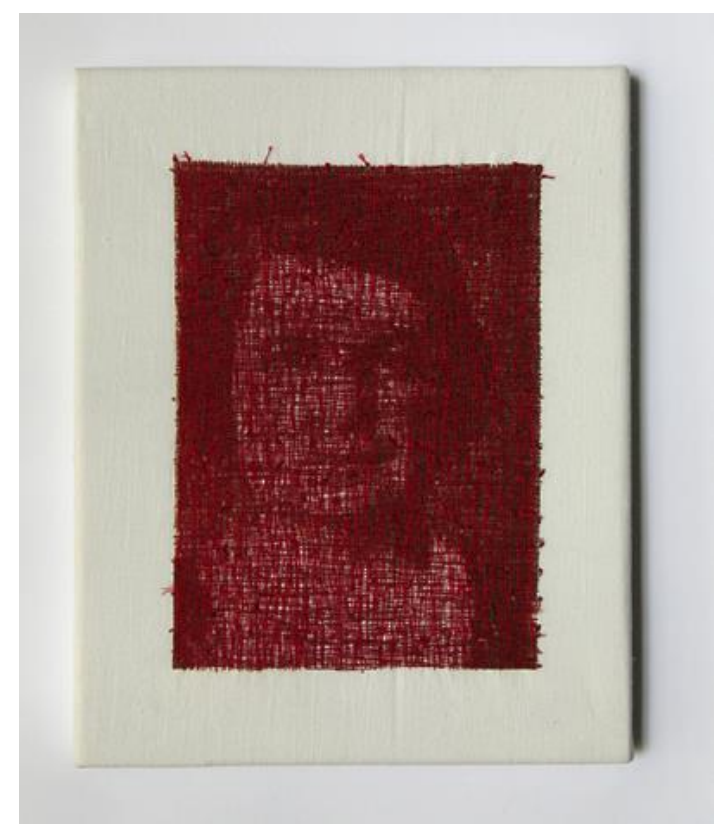

Fig. 4: A-mnesia, 2013. Transferencia sobre tela e hilo. 24 x19 cm. Imagen cortesía de la artista. Fotografía de Jesús Paniagua. 
no deja acceder a la imagen, descubre que esta ha sido superada, sobrepasada, olvidada y, por tanto, logra la comunicación del mensaje de la artista.

He querido destacar esta selección de obras de Romeu, extraídas de un grupo mucho mayor, por considerarlos ejemplos manifiestos de costura como escritura con la línea como base. Como se ha observado, la línea ha sido interpretada con parámetros lingüísticos, posee una gramática, una semántica y una pragmática propia y es la parte más superficial de la costura como escritura. Sin embargo, existe otra parte de la producción de nuestra artista que, como mencionaba en la introducción, surge de un segundo fundamento de la escritura en cuanto costura y se relaciona, ya no con el lenguaje sino con la narración. Aquí se percibe una profundidad mayor: mientras que la línea es la superficie, la sutura alcanza mayor calado debido a su conexión con la herida.

\section{S_u_t_u_r_a}

No es novedad alguna la relación de la costura con la herida, e incluso, con el trauma. Así la concibió Louise Bourgeois y tantos otros que vieron en la acción de coser una posibilidad de sanación o al menos de restauración. De aquí se deriva también el vínculo con la creación más alejada de la institución, aquella que, tan solo en las últimas décadas ha encontrado un lugar en el mercado del arte. Me refiero a la práctica denominada arte outsider. La Dra. Graciela García Muñoz la define en su tesis Procesos creativos en artistas outsiders como «el arte realizado en los márgenes, repertorios de formas surgidos de la necesidad de expresión, ajenos a los roles e intenciones del arte "profesionalizado"» (García Muñoz, 2010: 24).

Pues bien, la costura es uno de los instrumentos de expresión, normalmente utilizado por mujeres, emblemáticos de lo outsider. Existe en la propia condición de los marginados (en alusión a los márgenes de la definición) o - quizá más acertadamente por aludir no solo a los que están excluidos de facto, sino también a los que padecen la exclusión en su vertiente más sofisticada y más globallos subalternos, una herida ligada estrechamente con la invisibilidad.

Si en las obras de Romeu que revisábamos líneas arriba se lograba la invisibilidad de las imágenes sobrecosiéndolas y esto significaba aportar todavía una referencia a lo concreto, al individuo, no sucede así en las obras que comprendo bajo el epígrafe de la sutura. En estas opera una reducción importante que nos remite a una nueva materialización de la costura como escritura. Los protagonistas de las historias particulares se han abstraído, de manera que ahora se encuentran todos ellos formando parte de una sola narración. Romeu ha practicado una síntesis drástica que concluye en un único atributo fundamental de la condición de víctima: la sangre. Con ella escribirá ahora la costura:

[...] porque la sangre es preciosa, más preciosa que el oro y los diamantes. Porque toda la sangre es una: un solo estanque de vida repartido entre nuestras existencias separadas, pero unido por la naturaleza: prestada, no dada; repartida, confiada, para que la preservemos: parece que viva en nosotros, pero solamente lo parece, porque lo cierto es que nosotros vivimos en ella (Coetzee, 1990: 33).

Inspirada por el hecho de que la sangre es solo una, Romeu pivota de la línea a la sutura. Será esta la encargada de unir catárticamente las manchas de sangre de cada una de las víctimas en lo que 
denomino necrocostura. Esta estrategia de subsunción permite a la artista superar lo particular y establecerse en un campo de intensidad generado a partir de la inclusión.

Llegado este momento, veo preciso hacer una puntualización para la que resulta necesario introducir uno de los conceptos políticos de gran impacto para la escena global actual, puesto en juego en 2006 por el pensador camerunés Achille Mbembe y con el que amplía sustancialmente la noción de biopolítica enunciada por Michel Foucault. La necropolítica para Mbembe supone una radicalización de la soberanía en su capacidad de decidir quién vive y quién muere. Bajo esta perspectiva y con la licencia de omitir el notable desarrollo de Mbembe, se deduce que el anonimato de las víctimas es una de las condiciones indispensables para el mantenimiento del poder. Es habitual convivir con la tensión entre, por un lado, la voluntad de inexactitud de los medios (en su sentido más amplio) en el recuento de heridos y muertos y, por otro, la reivindicación continua de sus nombres y apellidos por parte de los allegados, en definitiva, la memoria.

La puntualización, por tanto, sería sobre el término anonimato. En la síntesis practicada por Romeu se da una reconciliación con la cualidad de anónimo, al contrario de lo que sucede en el memorial. Pensemos, por ejemplo, en el capítulo «La parte de los crímenes» de la obra 2666 donde Roberto Bolaño describe exhaustivamente durante más de trescientas páginas las apariciones de los cadáveres fruto de feminicidios en México desde enero de 1993 hasta finales de 1997. Los nombres de cada una de las mujeres y el último recuerdo que se tiene de ellas supone una resistencia a los instrumentos generadores de anonimato empleados por la necropolítica, pero el procedimiento del autor está basado en la diferencia. Mantener la heterogeneidad de las víctimas supone evitar la sutura.

Ahora bien, en el trabajo de Romeu la sutura no significa sanación, sino una estrategia de visualización que permite atender al conjunto en tanto anónimo sin obviar la procedencia de cada una de sus partes. La sutura no elimina ni esconde la herida, más bien la reunifica, la hace significativa en su suma. A diferencia de Bolaño, que rehúye el anonimato y la necropolítica que lo fuerza, Romeu reconoce dos tipos diferentes: un anonimato previo y constitutivo de la víctima y otro posterior fruto de la síntesis de su trabajo. El primero se refiere a la cotidianidad, a la falta de excepcionalidad de las vidas de las personas que serán convertidas en víctimas - algo que la artista representa frecuentemente con el color gris - mientras que el segundo alude a la ausencia de rasgos distintivos de cada una de las víctimas, unidas tan solo por la sangre.

La obra Exaltación [fig. 5] es un ejemplo paradigmático de estas ideas. Esta tela de gran formato que cuelga de techo a suelo está dinamizada internamente por la dialéctica entre lo individual y lo común. La sutura ha reunido las manchas de sangre de cada una de las víctimas que Romeu ha copiado literalmente de

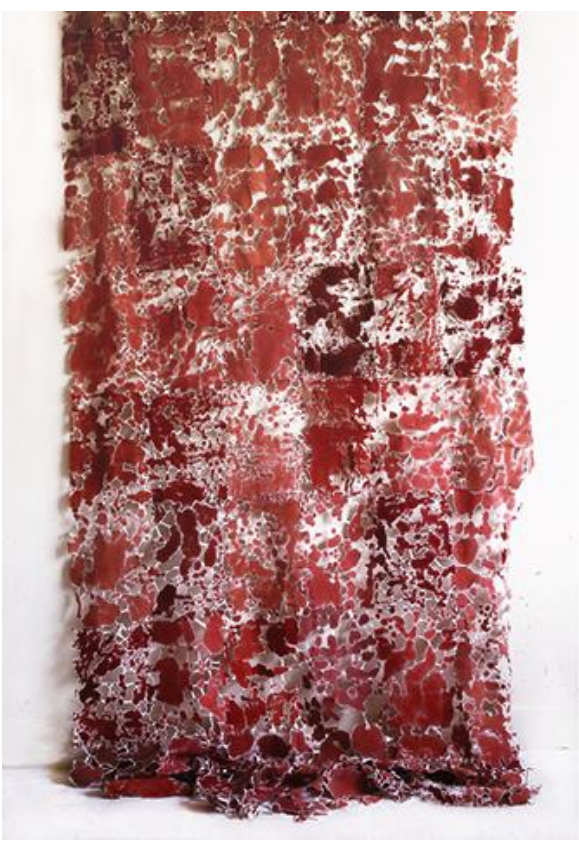

Fig. 5: Exaltación, 2010. Acrílico sobre tela. 266 x $126 \mathrm{~cm}$. Imagen cortesía de la artista. Fotografía de Jesús Paniagua. 
imágenes reales. Esas manchas tienen nombre y apellidos, sin embargo, la artista sumerge la soledad de cada una de ellas en una narración reconciliadora que trasciende sus contextos específicos.

De manera similar, en el libro de artista De la herida [fig. 6] es la sutura que une las páginas la que convierte en una sola la sangre decantada a través de la tela. Aquí la noción de narración queda, si cabe, más evidente. No se trata de la acumulación de historias sino de la referencia a todas ellas. La sangre que impregna la primera hoja es la misma que alcanza la última página, de manera que este libro cuenta la Historia común que comparten las víctimas.

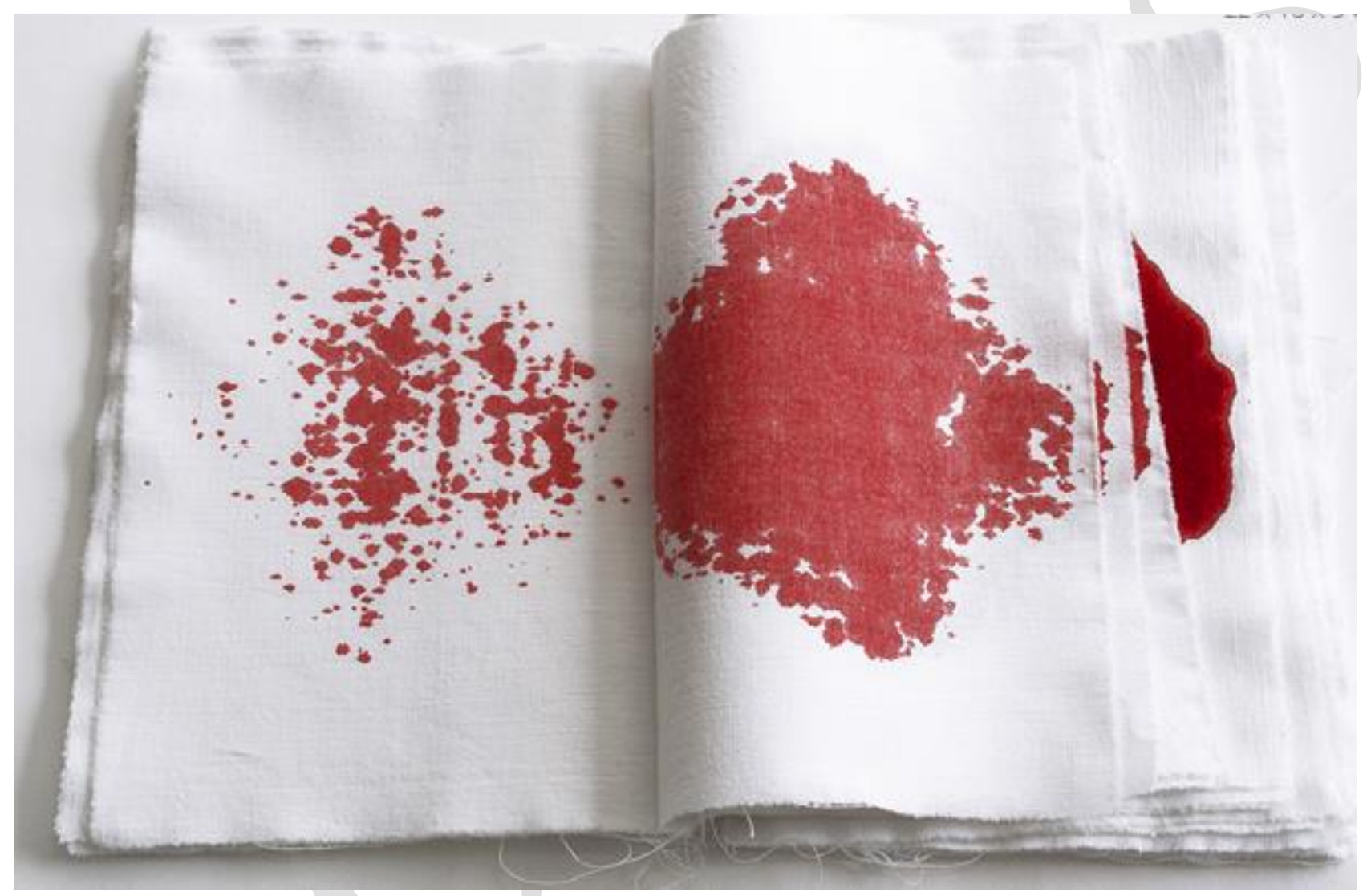

Fig. 6: De la herida, 2010. Acrílico sobre tela. 22 × 16 × 3 cm. Imagen cortesía de la artista. Fotografía de Jesús Paniagua.

Es probable que en el trabajo de los artistas plásticos se observe mejor que en ninguna otra creación el despliegue particular de cada una de las ideas que terminan por conformar un sistema. Las intuiciones en su estado germinal, las certezas más rotundas, los cuestionamientos de estas certezas, la reconfiguración de planteamientos iniciales o los hallazgos de nuevas vías de exploración quedan materializados en obras que, de ninguna manera, siguen una progresión lineal con un objetivo definido a lo largo de una trayectoria artística. Esta organicidad tan transparente de la obra plástica permite un análisis sumamente rico del proceso creativo. 
Así, en el trabajo de Romeu se pueden observar otros momentos diferentes que habitan terrenos colindantes al orden de ideas vertebrador que he querido exponer. Por ejemplo, en la serie de vestidos Desaparecidos [fig. 7] se incluyen algunos con rostros de personas no encontradas que suponen un estadio intermedio entre la alusión directa a las víctimas y su síntesis. Sin embargo, al mismo tiempo en esta serie se encuentran otros que corresponderían a un momento posterior a la síntesis: la desaparición. La obra de Romeu despliega en sus manifestaciones más recientes una tendencia hacia la extinción de la herida como se comprueba en el libro de artista Negación [fig. 8] del

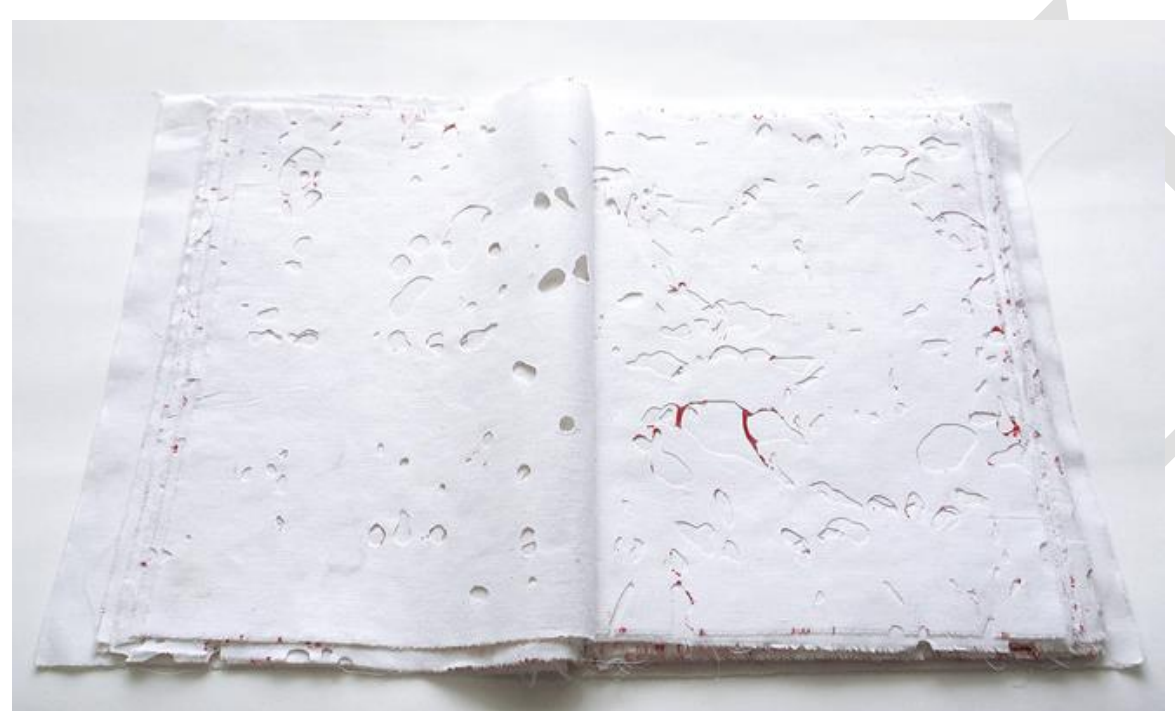

Fig. 8: Negación, 2010. Acrílico sobre tela. 30 × 22 × $2 \mathrm{~cm}$. Imagen cortesía de la artista. Fotografía de Jesús Paniagua.

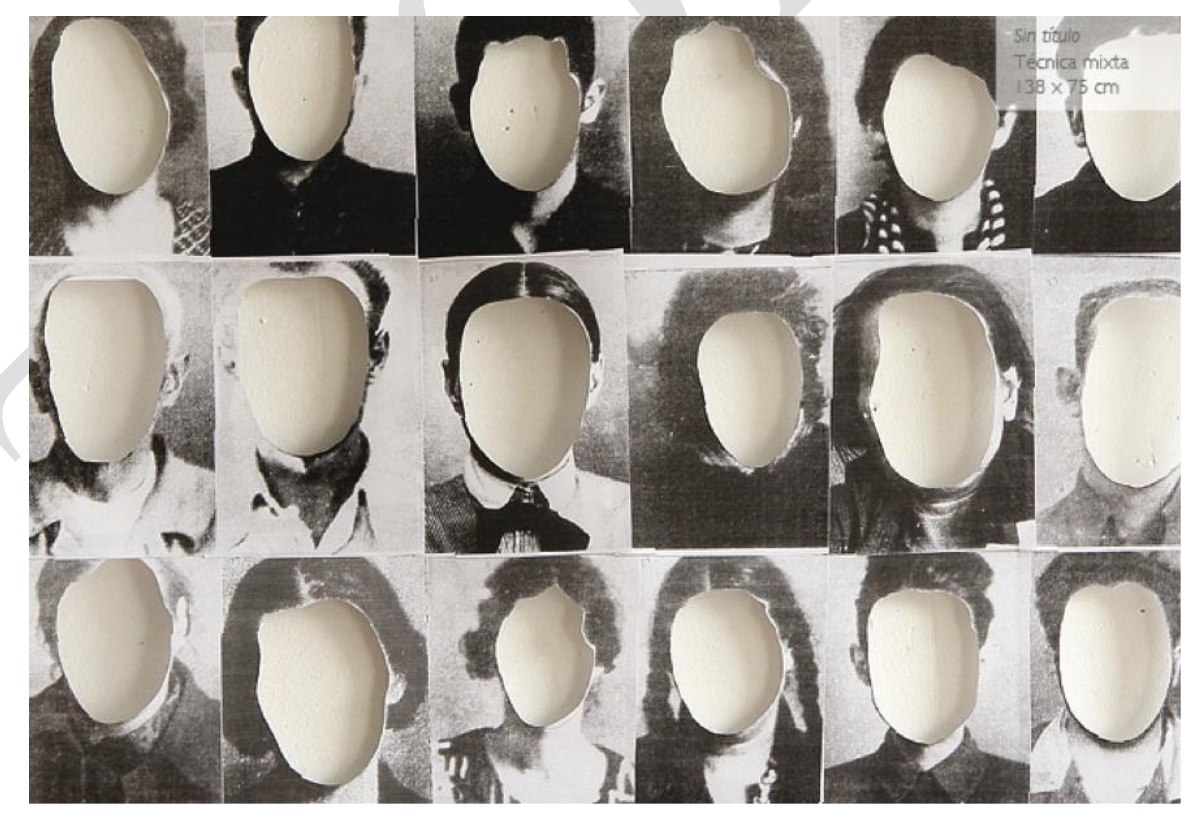

Fig. 9: Sin título, 2010. Técnica mixta. 138 x $75 \mathrm{~cm}$. Imagen cortesía de la artista. Fotografía de Jesús Paniagua.

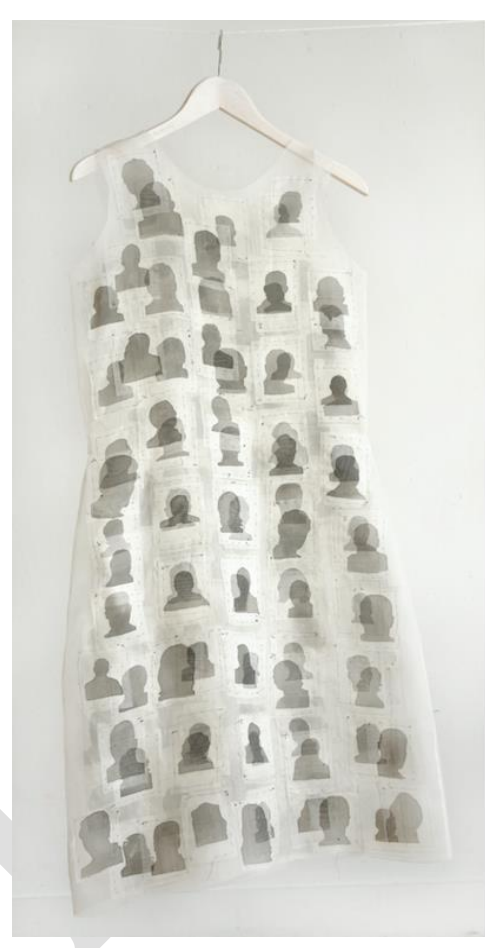

Fig. 7: Desaparecidos, 2005. Acrílico sobre seda. 100 × 55 x 3 $\mathrm{cm}$. Imagen cortesía de la artista.

Fotografía de Jesús Paniagua.

que se extrae minuciosamente la sangre previamente volcada sobre las páginas.

Un fenómeno similar de desaparición se aprecia en estas dos obras sin título [figs. 9 y 10] donde una resulta la transición hacia la otra si aplicáramos una secuencia lógica a un trabajo que, repetimos, no entiende de evoluciones lineales. Mientras que en la primera los rostros se han suprimido impidiendo el reconocimiento de cada una de las víctimas, en la segunda se ha borrado todo rastro quedando tan solo la forma que acogió la imagen. Las 
obras más recientes de Romeu continúan por este camino de abstracción que se traduce también en un giro cromático. El color rojo de la sangre deja paso progresivamente al blanco como símbolo de la extirpación de la herida [figs. $11 \mathrm{y}$ 12].

Asistimos así a la configuración más reciente derivada de la sutura. Su poder unificador ha desembocado en una nueva manifestación. Ha sido a través de la cohesión de las historias particulares en

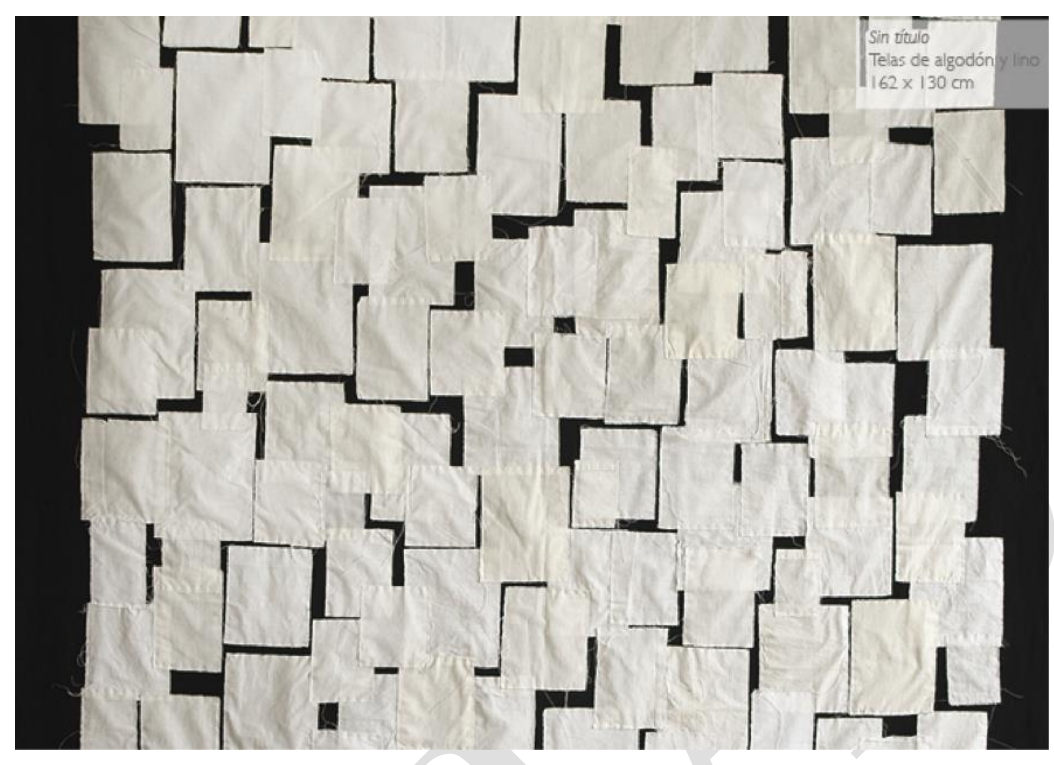

Fig. 10: Sin título, 2010. Telas de algodón y lino. 162 x $130 \mathrm{~cm}$. Imagen cortesía de la artista. Fotografía de Jesús Paniagua.

una única narración como se ha logrado superar la herida. Esta es una de las conclusiones principales del trabajo de Romeu en el momento presente y a la que, sin duda, seguirán nuevas vías de reflexión a medida que su obra continúe desarrollándose.

Se concluye, por tanto, que el escaso valor atribuido a la costura como medio artístico, derivado de su conexión con la subalternidad, no se corresponde con su potencialidad plástica ni teórica. Las dos bases que la constituyen como escritura conforman una estructura compleja capaz de resonar en los debates más rigurosos sobre arte contemporáneo.

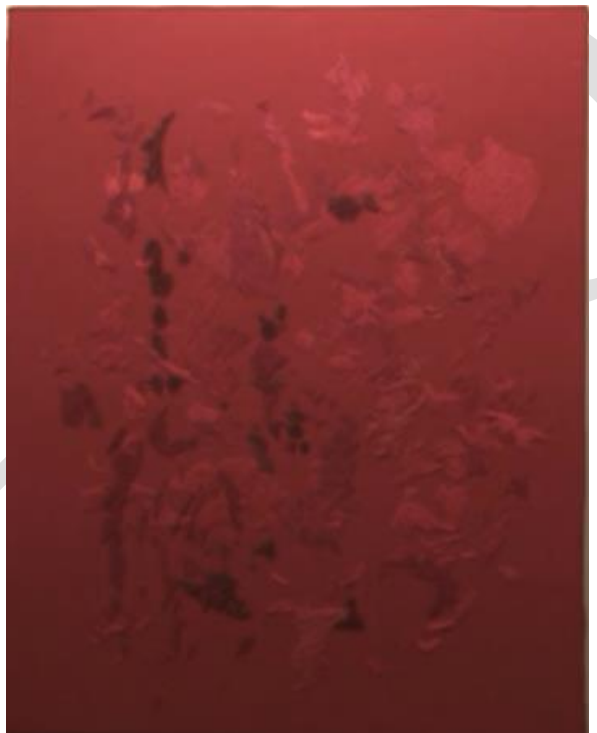

Fig. 11: Porque toda la sangre es una, 2014. Hilo bordado y tela. $81 \times 65 \mathrm{~cm}$. Imagen cortesía de la artista. Fotografía de Jesús Paniagua.
En el caso concreto de la obra de Romeu, la línea y la sutura han encontrado un terreno fértil en el que desarrollarse produciendo uno de los trabajos más relevantes en este medio del panorama artístico español y una referencia ineludible en cuestionamientos sobre la huella y la víctima desde el horizonte de las prácticas artísticas contemporáneas.

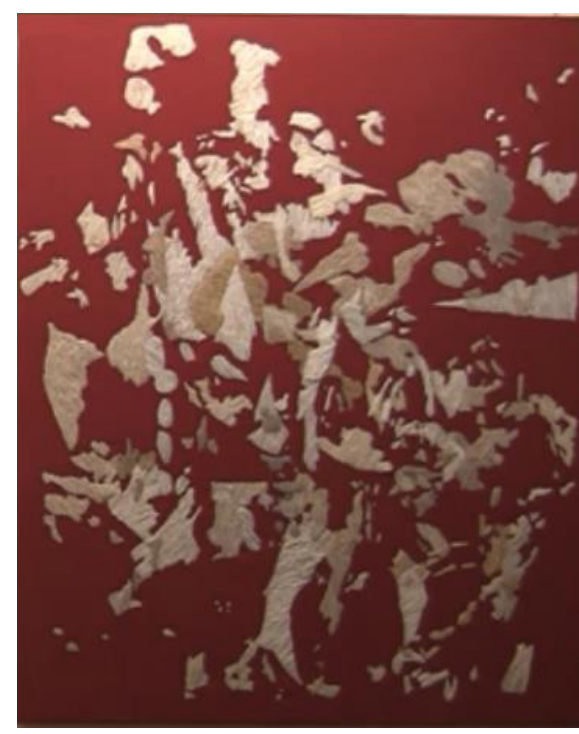

Fig. 12: Sin título, 2014. Hilo bordado y tela. 81 x $65 \mathrm{~cm}$. Imagen cortesía de la artista. Fotografía de Jesús Paniagua. 


\section{Bibliografía}

BoLAÑO, Roberto (2004): 2666. Barcelona, Anagrama.

CoetzeE, John Maxwell (1990): La edad de hierro. Mondadori, Barcelona, 2002.

DERRIDA, Jacques (1967): De la gramatología. México, Siglo XXI, 1998.

GARCíA MuÑOZ, Graciela (2010): Procesos creativos en artistas outsider, en http://eprints.ucm.es/ 11022/ (última consulta, 20-6-2016).

Mbembe, Achille (2006): Necropolítica seguido de Sobre el gobierno privado indirecto. Santa Cruz de Tenerife, Melusina, 2011.

ROMEU, Concha: Concha Romeu (web oficial), en http://www.concharomeu.com/ (última consulta, 20-6-2016).

SCHELLE, Karl Gottlob (1802): El arte de pasear. Madrid, Díaz \& Pons, 2013.

THOREAU, Henry David (1861): Walking, en http://www.gutenberg.org/ebooks/1022 (última consulta, 20-6-2016).

WALSER, Robert (1917): El paseo. Madrid, Siruela, 2a ed., 1997. 